\title{
Feijoa Sellowiana: Characteristics and Pharmacological Activities
}

\author{
Lydia Ferrara* \\ Department of Pharmacy, University of Naples Federico II, Italy \\ *Corresponding author: Lydia Ferrara, Department of Pharmacy, University of Naples Federico II, Italy
}

\begin{abstract}
ARTICLE INFO
Received: March 09, 2020

Published: March 26, 2020

Citation: Lydia Ferrara. Feijoa Sellowiana: Characteristics and Pharmacological Activities. Biomed J Sci \& Tech Res 26(5)-2020. BJSTR. MS.ID.004400.

\section{ABSTRACT}

Feijoa sellowiana Berg is a fruit very suitable for human consumption, rich in nutrients for good nutrition, with a very pleasant taste and aroma. Studies conducted on the nutritional value of the fruit have highlighted the presence of essential elements: amino acids, vitamins, mineral salts, terpenes, polyphenols, functional ingredients and, very importantly, the presence of iodine. The functional compounds have shown a powerful antibacterial activity against some Gram + and Gram- bacterial strains, antioxidant, hypoglycemic, hypocholesterolemic, cardioprotective, antitumor activity. Its presence on the markets is very rare as it is easily perishable due to the presence of an enzyme, the polyphenol oxidase which causes the rapid browning of the fruit with loss of sensory properties and nutritional value.
\end{abstract}

Keywords: Feijoa Fruit; Food; Pharmacological Properties; Extracts with Water and Solvents; Nutraceutical Products

\section{Introduction}

The Feijoa sellowiana Berg also referred to as Acca sellowiana is an evergreen shrub of the Mirtaceae family, native to southern Brazil, northern Argentina, western Paraguay and Uruguay. Commercially its fruit, an oval berry, of an intensely perfumed dark green color, is highly appreciated in New Zealand, Russia, Israel, Germany, while in Italy it is difficult to find [1]. The first samples were collected in Brazil by Friedrich Sellow German naturalist, explorer of Brazil, from which the name of Sellowiana derives, while the name Feijoa derives from G. de Silva Feio, director of the Museum of Natural History of San Sebastiano. There are several types of Feijoa and the best known are the cultivars: Apollo, Colidge, Moore Triumph, Gemini, Mammoth. It reaches 3-4 $\mathrm{m}$ in height with a crown opening of 3-5 m; the leaves are opposite petiolate, consistent, of an intense green color above, light green below. The flowers are intensely odorous, hermaphrodite, single or gathered in groups of two-three, with a waxy white corolla formed by four petals, at first stretched out, then they are rolled into a cylinder and, after pollination, the internal part of them takes on an intense purple color. The stamens 70-80 are blood red in color and hide the pistil with a quadrilocular ovary; the fruit is a dark green berry when fully ripe, of different shape and weight depending on the cultivars while the whitish pulp containing numerous seeds are very sweet and fragrant [2-4].

\section{Chemical Composition}

Research carried out to find out the nutritional value and organoleptic characteristics of this fruit has highlighted the presence of essential amino acids, vitamins and in particular vitamin C, carotenoids, minerals, such as potassium, polyphenols and flavonoids, while very reduced it is the share of lipids and cholesterol is absent. Amino acids are present in both linear and branched chains with arginine, aspartic acid and Gaba in high concentration [5]; among the trace elements it is interesting to note that the $\mathrm{Na} / \mathrm{K}$ ratio is in favor of $\mathrm{K}$ while $\mathrm{Ca} / \mathrm{Mg}$ are in equal concentration; among the flavonoids are Rutina Miricetina, Galangina, Quercitina and Kamferolo [6]. The fruits of Feijoa, and in particular the skins, contain high concentrations of polyphenols such as catechins, leucoanthocyanins, naphthoquinones [7]; the leaves also contain catechins, proanthocyanins and flavonoids [8]. Feijoa sellowiana also contains 
particular functional compounds such as folic acid and iodine in a concentration of $3 \mathrm{mg} / 100 \mathrm{~g}$ [9]. The peels of the fruit subjected to hydro distillation in Clevenger's apparatus provided a very fragrant oil which, on gas chromatographic analysis, revealed the presence of over 60 constituents among which the sesquiterpenes, caryophyllene, ledene $\alpha$-humulene, $\beta$-elemene and $\delta$ - cadinene, are present in greater concentration $[10,11]$.

\section{Pharmacological Properties}

Feijoa sellowiana has been the subject of many researches for its pharmacological potential, such as antioxidant and antibacterial activity; defense activity against pathogens (antibiotics); inhibition of the development of other plant species (allelopathy), anticancer activity, etc. ... The different components of the fruit, leaves, branches have been analyzed to clarify the mechanisms that underlie their antibiotic, hypoglycaemic, hypocholesterolemia, cardioprotective, anti-free radical, and anti-cancer potential. The plant extracts obtained both in aqueous solution and in various solvents are also rich in active principles with emollient, softening, tonic, refreshing, elasticizing, dermo-purifying and stimulating functions that allow to consider their use not only in products for exclusive pharmaceutical use but also cosmetic. The acetone extract of the fruit attracted the attention of researchers having highlighted antioxidant and antibacterial activity against both Gram + and Gram- bacteria such as Staphylococcus aureus, Enterococcus faecalis, Proteus mirabilis, Proteus vulgaris, Pseudomonas aeruginosa, Salmonella typhi $[12,13]$. During this research it was also possible to observe some activity towards various fungal species: Candida albicans, Botrytis cinerea and Rhyzoctonia solani [14]. This fruit is very rich in the pulp and skin of phytochemicals with strong pharmacological activity: the polyphenols, which are well known for their antioxidant activity. In an aqueous-methanolic extract of leaves and branches of Feijoa sellowiana in which flavones have been identified as avicularin which prevents the accumulation of lipids; kamferol with anticancer activity; quercitin which manifests antihypertensive and antiatherogenic effects, prevents endothelial dysfunction and protects the myocardium from ischemic damage; gallic or ellagic acid derivatives such as casuarina, nilocitina, strictinin; esters of ellagic acid. This extract was not toxic up to a dose of $5 \mathrm{~g} / \mathrm{kg}$ in weight and showed significant analgesic, anti-inflammatory, anti-ulcer, antioxidant and hepatoprotective activities. In a histopathological study for liver tissues, he revealed an improvement in liver damage induced by oral paracetamol administration [15-17]. The considerable concentration of active phytochemicals present in the aqueous extract has highlighted the beneficial effects of Feijoa sellowiana also at intestinal level, stimulating the development of probiotic bacteria that are part of the intestinal flora and provide for the maintenance of the good state of health of the intestine itself and preventing the increase of pathogenic bacteria [18]. In some studies, it is reported that gallic acids and catechins are responsible for the growth of probiotic bacteria, bifidus bacteria and lactobacilli, such as Lactobacillus hilgardii [19]. Even the flavones present in the extract contribute to the growth of bifidus probiotic bacteria, thanks to the action of the enzyme beta- glucosidase which, hydrolyzing them in aglyconic form, allows easy absorption by bacteria $[20,21]$.

In the extract of the fruit there are both pectic and hemicellulosic polysaccharides which have been evaluated experimentally for the growth of some species of Bacteroides, anaerobic Gram- bacteria, which constitute the most consistent part of the gastrointestinal flora of mammals. These bacteria play a role fundamental in modifying the most complex molecules in the host intestine, influencing the intestinal immune system. Several species of commensal Bacteroides were screened for growth in culture using preparations of both polysaccharides: a preference for pectic polysaccharides and a more limited growth with hemicellulosic ones was highlighted. The bacterial species used also showed a differential hydrolysis of pectic polysaccharides, which could influence the structure and metabolic activities of the human intestinal microbiota. Bacteroides variceppi have been studied for their probiotic type attributes [22]. A methanolic aqueous extract obtained from the fruit leaves has been tested on human osteoblastic cell lines to evaluate its effect in view of a possible prevention and treatment of osteoporosis. The extract was seen to significantly increase the mineralization of cultured human bone cell and this activity was due to the presence in the extract of a high content of polyphenols including 3-0-beta-glucopyranoside 3-methoxyellagic which was completely identified [23].

\section{Conclusion}

In the countries of origin, Feijoa sellowiana is a fruit that is eaten as it is deprived of its peel or is used for the preparation of jams, fruit juices and ice cream; also the dried leaves provide a sweet and fragrant infusion which is used for the treatment of diabetes mellitus or for its action to lower the cholesterol content considered a risk factor for cardiovascular diseases; the same flowers are added to salads for their particular aroma or are candied and used in pastry. The chemical composition of the fruit and its pharmacological properties are such as to consider its use not only for the preparation of supplements but also for drugs for the prevention of many pathologies or as pharmaceutical adjuvants in the case of prolonged treatments. In addition to the food and pharmaceutical sector, the fruit extracts are indicated for the preparation of creams with moisturizing, emollient and antibacterial action; the use has been recently considered as protective in solar products due to their proven high absorption in the UV region. In Italy Feijoa is mainly used as an ornamental plant and therefore the study of the chemical composition and organoleptic characteristics of these fruits is indispensable for informing consumers about the nutri- 
tional properties of the fruit. Also, a better knowledge of the possibility of industrial processing is important, to promote a cultivation necessary to satisfy all eventual requests.

\section{Conflict of Interest}

The author declares she has no conflicts of interest.

\section{References}

1. Cacioppo 0 (1986) La Feijoa. Practical Manual, Reda Edition 1986.

2. Pugliano G (1973) Floral biology of Feijoa sellowiana cultivar, Agricultural Technique n1.

3. Pugliano G (1980) La Feijoa. Magazine of fruit growing and horticulture 42: $1-54$.

4. Pugliano G (1987) La Feijoa sellowiana. Main cultural characteristics and perspectives for the immediate future. Riv Agriculture Research 13: 69-70.

5. Ferrara L, Dini I, Montesano D (1998) Determination by HPLC of the amino acids of the fruit of Feijoa sellowiana, Acts VIII Italian-Latin American Congress of Ethnomedicine Salerno p. 12-15.

6. Ferrara L, Schettino O, Montesano D, Viti L (1999) Analytical study of the flavonoids of Feijoa sellowiana Riv. Agriculture and research 183: 31-34.

7. Nakashima H (2001) Biological activity of Feijoa peel extracts. The Progress Report of the 1999 Survey of the Research Project Social Homeostasis of Small Islands in an Island-zone 34: 169-175.

8. Vanidze MR (1991) Quantitative changes in foliar catechins, proanthocyanidins, and flavonols. Subtrop Kul't 3: 80-81

9. Ferrara L, Montesano D (2001) Nutritional characteristics of Feijoa sellowiana fruit. The iodine contents. Riv Sci Aliment 30: 353-356.

10. Shaw GJ, Allen JM, Yates MK (1989) Volatile flavour constituents in the skin oil from feijoa sellowiania. Phytochemistry 28(5): 1529-1530.

11. Fernandez X, Loiseau AM, Poulain S, Lizzani-Cuvelier L, Monnier Y (2004) Chemical composition of the essential oil from Feijoa (Feijoa sellowiana Berg.) peel. J Ess Oil Res 16(3): 274-275.

ISSN: 2574-1241

DOI: $10.26717 / B J S T R .2020 .26 .004400$

Lydia Ferrara. Biomed J Sci \& Tech Res

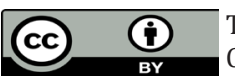

This work is licensed under Creative Commons Attribution 4.0 License

Submission Link: https://biomedres.us/submit-manuscript.php
12. Vuotto ML, Basile A, Moscatello V, De Sole P, Castaldo Cobianchi R, et al. (2000) Antimicrobial and antioxidant activities of Feijoa sellowiana fruit, Int J Antimicrob Agents 13: 197-201.

13. Basile A, Conte B, Rigano D, Senator F, Sorbo S (2010) Antibacterial and antifungal properties of acetonic extract of Feijoa sellowiana fruits and Its effect on Helicobacter pylori growth. J Med Food 13(1): 189-195.

14. Motohashi N, Kawase M, Shirataki Y, Tani S, Saito S, et al. (2000) Biological activity of Feijoa peel extracts. Anticancer Res 20(6B): 4323-4329.

15. Fujimori K, Shibano M (2013) Avicularin, a plant flavonoid, suppresses lipid accumulation through repression of $\mathrm{C} / \mathrm{EBP} \alpha$-activated GLUT4mediated glucose uptake in 3T3-L1 cells. J Agric Food Chem 61(21): 5139-5147.

16. Bischoff SC (2008) Quercetin: potentials in the prevention and therapy of disease. Curr Opin Clin Nutr Metab Care 11(6): 733-740.

17. Perez-Vizcaino F, Duarte J (2010) Flavonols and cardiovascular disease. Mol Aspects Med 31(6): 478-494.

18. Kolida S, Saulnier DM, Gibson GR (2006) Gastrointestinal microflora: Probiotics. Adv Appl Microbiol 59: 187-219.

19. Alberto MR, Farias ME, Nadra MCM (2001) Effect of gallic acid and cathechin on Lactobacillus hilgardii $5 \mathrm{w}$. Growth and metabolism of organic compounds. J Agric Food Chem 49(9): 4359-4363.

20. Marteau PR, deVrese M, Cellier CJ, Schrezenmeir J (2001) Protection from gastrointestinal diseases with the use of probiotics. Am J Clin Nutr 73(2 Suppl): 430S-436S.

21. Sarowska J, Choroszy-Król I, Regulska-Ilow B, Frej-Mądrzak M, Jama Kmiecik A (2013) The therapeutic effect of probiotic bacteria on gastrointestinal diseases. Adv Clin Exp Med 22(5): 759-766.

22. Bell TJ, Draper SL, Centanni M, Carnachan SM, Tannock GW, et al. (2018) Characterization of Polysaccharides from Feijoa Fruits (Acca sellowiana Berg.) and Their Utilization as Growth Substrates by Gut Commensal Bacteroides Species. J Agric Food Chem 66(50): 13277-13284.

23. Ayoub NA, Hussein SA, Hashim AN, Hegazi NM, Linscheid M, et al. (2009) Bone mineralization enhancing activity of a methoxyellagic acid glucoside from a Feijoa sellowiana leaf extract. Pharmazie 64(2): 137141.

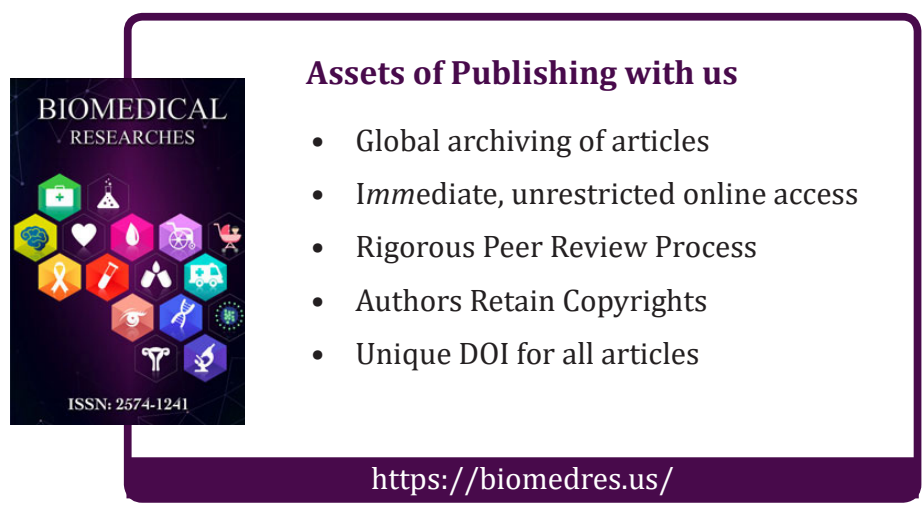

